\title{
Effect of preservative removal from fixed-combination bimatoprost/timolol on intraocular pressure lowering: a potential timolol dose-response phenomenon
}

This article was published in the following Dove Press journal:

Clinical Ophthalmology

3 March 2016

Number of times this article has been viewed

\author{
Jie Shen' \\ Marina Bejanian² \\ 'Department of Translational Sciences, \\ ${ }^{2}$ Department of Ophthalmology \\ Clinical Development, Allergan plc, \\ Irvine, CA, USA
}

Purpose: Many patients with glaucoma require combination therapies to achieve target intraocular pressure (IOP) and preserve visual function. Ocular hypotensives often contain a preservative (eg, benzalkonium chloride $[\mathrm{BAK}]$ ), but preservative-free (PF) formulations have been developed for patients with sensitivity. A Phase III study found the efficacy of bimatoprost $0.03 \% /$ timolol $0.5 \%$ (bim/tim, Ganfort ${ }^{\mathbb{R}}$ ) PF to be equivalent to that of preserved $\mathrm{bim} / \mathrm{tim}$, although a trend favoring bim/tim PF was observed. As BAK is a corneal penetration enhancer, this literature review aims to explain these findings by exploring the relationship between timolol concentration and its IOP-lowering effect.

Methods: Systematic searches were performed in Scopus and PubMed for clinical trials published in English between 1960 and July 2014 using the keywords "timolol", "intraocular pressure", and the concentrations " $1 \%, 0.5 \%$, OR $0.25 \%$ ". Articles that directly compared IOP-lowering effects of $\geq 2$ concentrations of timolol were identified by manual screening, and cross-checked for duplication.

Results: Seventeen studies that included 10-371 patients were evaluated; the majority were randomized (16/17), double-masked (14/17), and enrolled patients with open-angle glaucoma or ocular hypertension (12/17). All studies investigated timolol in preserved formulations. Timolol concentrations tested ranged from $0.008 \%$ to $1.5 \%$. Of 13 studies comparing timolol $0.25 \%$ versus $0.5 \%$, two found the $0.25 \%$ dose to have greater IOP-lowering effects, and three reported the opposite; eight reported similar IOP lowering. Results also indicate that timolol $0.5 \%$ may be more effective than higher concentrations.

Conclusion: The evidence suggests that timolol may have an inverted U-shaped dose-response curve, and that its optimal IOP-lowering concentration is between $0.25 \%$ and $0.5 \%$. Compared with bim/tim, removal of the permeability enhancer BAK in bim/tim PF could have resulted in a lower timolol concentration at the target site, bringing the effective concentration within the $0.25 \%-0.5 \%$ range and enhancing the efficacy of bim/tim PF.

Keywords: glaucoma, intraocular pressure, timolol, bimatoprost, preservative, dose-response

\section{Introduction}

Worldwide, open-angle glaucoma (OAG) is estimated to affect almost 45 million adults over the age of 40 years, and the number is expected to reach 59 million by $2020 .{ }^{1}$ Since the loss of vision associated with glaucoma is irreversible, ${ }^{2}$ early diagnosis and treatment are key to preserving visual function. Because intraocular pressure (IOP) is a major risk factor in glaucoma and glaucoma suspects, all currently marketed treatments for glaucoma aim to lower IOP. Accordingly, the administration of topical agents that reduce the production of aqueous humor and/or increase outflow is the mainstay of therapy. ${ }^{2-6}$

\footnotetext{
Correspondence: Jie Shen

Department of Translational Sciences, Allergan plc, 2525 Dupont Drive,

Irvine, CA 92612, USA

Tel + I 7142464989

Fax +I 7|4 2465580

Email shen_jie@allergan.com
}

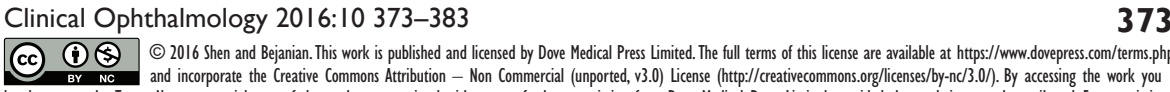
hereby accept the Terms. Non-commercial uses of the work are permitted without any further permission from Dove Medical Press Limited, provided the work is properly attributed. For permission for commercial use of this work, please see paragraphs 4.2 and 5 of our Terms (https://www.dovepress.com/terms.php). 
Multidose formulations of topical antiglaucoma medications contain preservatives, of which the most commonly used is benzalkonium chloride (BAK), a potent bactericidal and fungicidal agent. ${ }^{7,8}$ The majority of patients tolerate BAK, but it has been associated with ocular sensitivity in some cases..$^{9-12}$ Patients who require multiple medications to reach/maintain target IOP may be at higher risk of BAK sensitivity, as are those with severe dry eye disease because of reduced dilution in the tear film. ${ }^{9}$ Consequently, preservatives causing less irritation, as well as many singledose, preservative-free $(\mathrm{PF})$ formulations, have been developed. In clinical trials and clinical practice, PF formulations have demonstrated noninferior or equivalent efficacy to their respective preserved formulations, with potential for a reduced incidence of ocular adverse events. ${ }^{13-22}$

Bimatoprost/timolol (bim/tim) ophthalmic solution $\left(\right.$ Ganfort $^{\circledR}$; Allergan plc, Irvine, CA, USA) is a fixedcombination formulation of bimatoprost $0.03 \%$ (a synthetic prostamide) and timolol $0.5 \%$ (a nonselective $\beta$-adrenergic receptor antagonist) preserved with $\mathrm{BAK} .{ }^{23}$ Clinical trials have demonstrated that when dosed once daily, the fixed combination produces greater IOP reduction than each of the active components dosed as monotherapy. ${ }^{24,25}$ Accordingly, $\mathrm{bim} / \mathrm{tim}$ is used in a number of countries worldwide to treat patients with primary OAG (POAG) or ocular hypertension (OHT) who do not reach target IOP with monotherapy. However, because of the increasing awareness of patient sensitivity to preservatives, bim/tim PF (Allergan plc, Irvine, CA, USA) was developed; this PF formulation is identical to the original bim/tim formulation, except for the removal of $50 \mathrm{ppm}$ of BAK.

In a 12-week, multicenter, randomized, Phase III study of 561 patients with OAG or OHT, bim/tim PF demonstrated noninferiority and equivalence to bim/tim in terms of IOPlowering efficacy (without significant differences in safety/ tolerability), ${ }^{26}$ which led to its marketing approval in the European Union in September 2013. ${ }^{27}$ Despite these findings, when the between-treatment difference in average eye IOP was compared, a consistent trend toward lower IOP favoring bim/tim PF over bim/tim was observed in seven of the nine time points measured. ${ }^{26}$ This observation suggested that BAK removal might have enhanced the efficacy of bim/tim. Given that BAK is a well-known permeability enhancer that has been reported to increase drug penetration into ocular tissues, ${ }^{28-31}$ it was surprising that bim/tim PF produced a greater IOP-lowering effect than the bim/tim formulation containing BAK. ${ }^{26}$

A preliminary literature search exploring possible explanations for this clinical observation found data suggesting that timolol in preserved ophthalmic solutions may display an inverted, U-shaped dose-response curve for IOP lowering, with an optimal concentration between $0.25 \%$ and $0.5 \% .^{32}$ Removal of BAK from $0.5 \%$ timolol ophthalmic solution formulations could reduce timolol bioavailability enough to achieve a concentration that optimizes intraocular efficacy. ${ }^{32}$ This literature review aims to explain the findings of the Phase III study demonstrating enhanced efficacy of bim/tim PF over preserved bim/tim by exploring the relationship between the concentration of timolol in preserved ophthalmic solutions and its IOP-lowering efficacy.

\section{Methods}

\section{Study selection}

An initial search of the literature for timolol dose-response in humans was performed in Scopus (Elsevier, Philadelphia, PA, USA). Articles that were published in English between 1960 and July 2014 were identified using the keywords "timolol AND (intraocular pressure OR IOP) AND human (or derivatives) AND ( $1 \%$ OR $0.5 \%$ OR $0.25 \%$ )", and screened for relevance to IOP lowering after ocular instillation of topical timolol $0.25 \%, 0.5 \%$, or $1.0 \%$. Similarly, a literature search spanning the years 1960 to July 2014 was conducted in PubMed (http://www.ncbi.nlm.nih.gov/pubmed) using the keywords "timolol AND (intraocular pressure OR IOP) AND (1\% OR 0.5\% OR 0.25\%)", with filters set to display articles involving human patients in clinical trials published in English. Articles that reported direct comparisons of the effect of at least two concentrations of timolol on IOP in adult patients were included. Studies in which patient subgroups received a higher concentration of timolol after responding poorly to an initial lower concentration were excluded.

\section{Results and discussion Selected studies}

Given its long history in the management of glaucoma, many reports of the IOP-lowering effects of timolol have been published, but only a few provide data related to dose response. The Scopus search identified 548 citations, eleven of which contained relevant studies. A comparable search in PubMed yielded 607 references, including ten relevant clinical trials. Accounting for overlap, the Scopus and PubMed searches together found a total of 17 relevant studies (Figure 1).

A summary of each of the 17 publications identified is presented in Table 1. All trials were randomized except one, ${ }^{33}$ and 14 were double-masked. ${ }^{34}{ }^{47}$ Eight studies included parallel groups, ${ }^{34,37,41,43,44,46-48}$ six involved dose escalation, $33,35,38,42,45,49$ and three had one or two crossover(s). ${ }^{36,39,40}$ Five studies enrolled healthy volunteers, ${ }^{34,38,42,43,49}$ whereas the other 


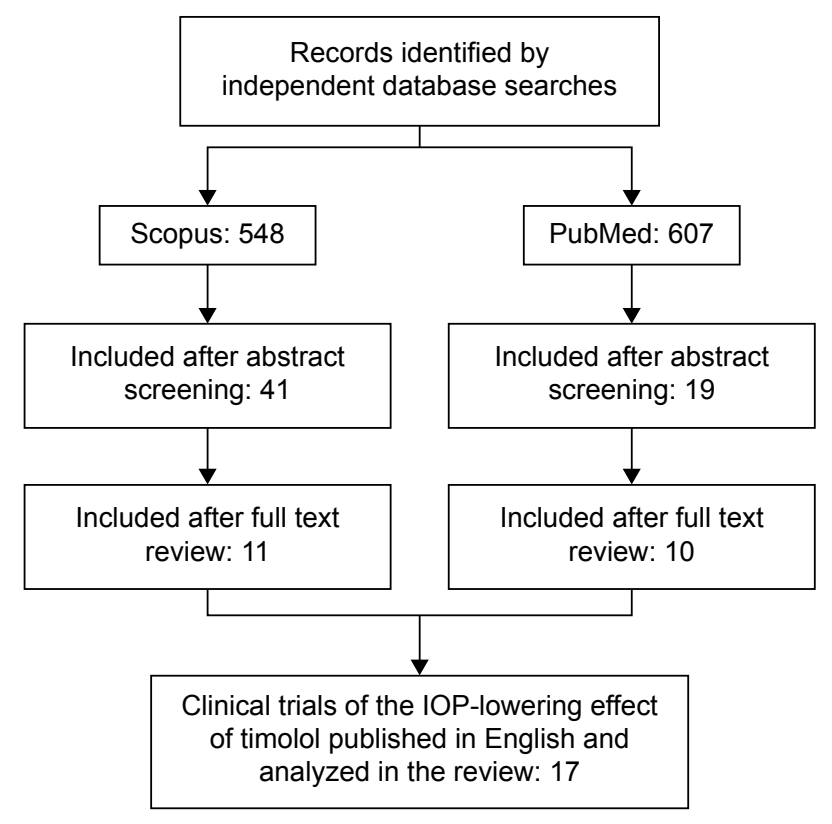

Figure I Summary of the article selection process. Abbreviation: IOP, intraocular pressure.

12 enrolled patients with OAG or OHT. Sample size ranged from ten to 371 patients.

\section{Overall IOP response to topical timolol}

Timolol is commonly prescribed as a $0.25 \%$ or $0.5 \%$ preservative-containing (usually BAK) ophthalmic solution. However, the selected studies covered a broader range of concentrations: $0.008 \%, 0.025 \%, 0.0625 \%, 0.08 \%, 0.1 \%$, $0.125 \%, 0.25 \%, 0.5 \%, 1.0 \%$, and $1.5 \%$ (Table 1 ). Nine studies measured IOP after weeks to months of timolol administration once $^{40,48}$ or twice ${ }^{33,35-37,41,44,45}$ daily. The remaining eight studies assessed the short-term (ie, within $\leq 28$ hours) IOP-lowering effect following a single application. ${ }^{34,38,39,42,43,46,47,49}$

All studies that evaluated the efficacy of timolol over weeks or months found that the concentrations tested (ie, $0.1 \%$, $0.25 \%, 0.5 \%$, and $1 \%$ ) provided statistically significant IOP reductions compared with baseline and/or controls (untreated or placebo-treated eyes), regardless of the instillation schedule (ie, once versus twice daily). ${ }^{33,35-37,40,41,44,45,48}$ However, results of short-term studies varied, depending on the study population. In patients with elevated IOP, concentrations of $0.1 \%, 0.25 \%, 0.5 \%, 1.0 \%$, and $1.5 \%$ provided statistically significant IOP reductions compared with baseline and/or controls (untreated or placebo-treated eyes). ${ }^{34,38,43,46,47}$ Even a concentration as low as $0.008 \%$ (administered as gel or solution) was effective in lowering IOP in patients with OHT and a baseline IOP $>22 \mathrm{mmHg}$, compared with placebo controls. ${ }^{39}$ In contrast, studies of healthy volunteers with baseline IOP of approximately $13-14 \mathrm{mmHg}$ reported no significant
IOP-lowering effect when treated with timolol $0.008 \%$ or $0.025 \%,{ }^{42}$ or $0.0625 \%, 0.125 \%$, or $0.25 \%{ }^{49}$

\section{Determining the optimal dose - timolol $0.5 \%$ versus higher concentrations}

Four studies compared the IOP-lowering effect of timolol ophthalmic solution at concentrations of $0.5 \%$ or greater and found that timolol $0.5 \%$ was as effective as or more effective than higher concentrations. Three of these studies involved a single application of drug. ${ }^{38,46,47}$ In a parallelgroup, single-dose study in 30 patients with OAG, timolol $0.5 \%$ was as effective as or numerically more effective than timolol $1.5 \%$ at six of eight time points measured (Figure 2A) ${ }^{46}$ In a similarly designed study in 20 patients with $\mathrm{OAG}$, timolol $0.5 \%$ was as effective as or numerically more effective than timolol 1.0\% at the 4-, 12-, and 24-hour time points (Figure 2B). ${ }^{47}$ Also, in a dose escalation study in 30 healthy volunteers, Katz et $\mathrm{al}^{38}$ found that IOP reduction from baseline was numerically greater at 3,5, and 7 hours after a single application of timolol $0.5 \%(25 \%, 26 \%$, and $23 \%)$, compared with timolol $1.0 \%(23 \%, 19 \%$, and $22 \%)$ or $1.5 \%(24 \%, 17 \%$, and $17 \%)$, respectively. Timolol $0.5 \%$ was also numerically more effective than timolol $1.0 \%$ at 2 hours postinstillation (Figure 2C). The fourth and most clinically relevant study involved administration of timolol $0.5 \%$ and $1.0 \%$ twice daily for 1 week in a dose escalation design, ${ }^{45}$ and found that patients with OHT or OAG had a numerically lower mean IOP at four of six postinstillation time points during treatment with timolol $0.5 \%$ than during treatment with timolol 1.0\% (Figure 2D). ${ }^{45}$

The consistent findings suggest that on a concentration basis, timolol $0.5 \%$ is more effective than higher concentrations. Such an inverted U-shaped dose-response relationship, in conjunction with the systemic cardiovascular risk associated with timolol as a nonselective $\beta$-adrenoceptor antagonist, ${ }^{50-56}$ explains why timolol is not prescribed at a dose strength higher than $0.5 \%$.

\section{Determining the optimal dose - timolol $0.25 \%$ versus $0.5 \%$}

Of the 17 studies, 13 compared timolol $0.25 \%$ and $0.5 \%$, currently the most commonly used concentrations. Among these, two studies showed that timolol $0.25 \%$ was either significantly or numerically more effective than timolol $0.5 \%$ in IOP lowering. The first, a parallel-group study of timolol administered twice daily over 12 months, indicated that when statistically significant differences were found between doses, they always favored timolol $0.25 \%$ (Figure 3A). ${ }^{41}$ The second, a double-masked, three-phase study of the 


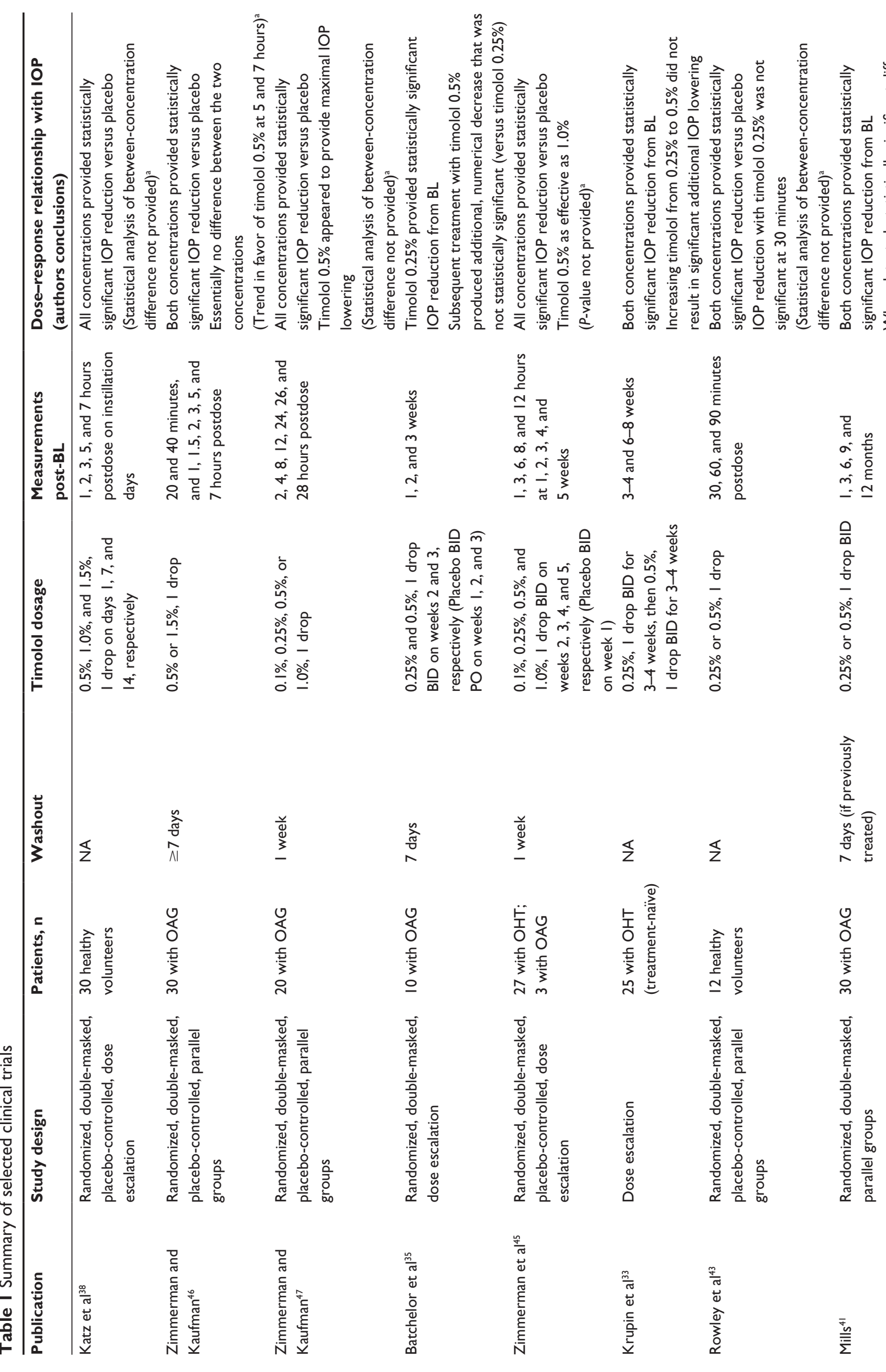



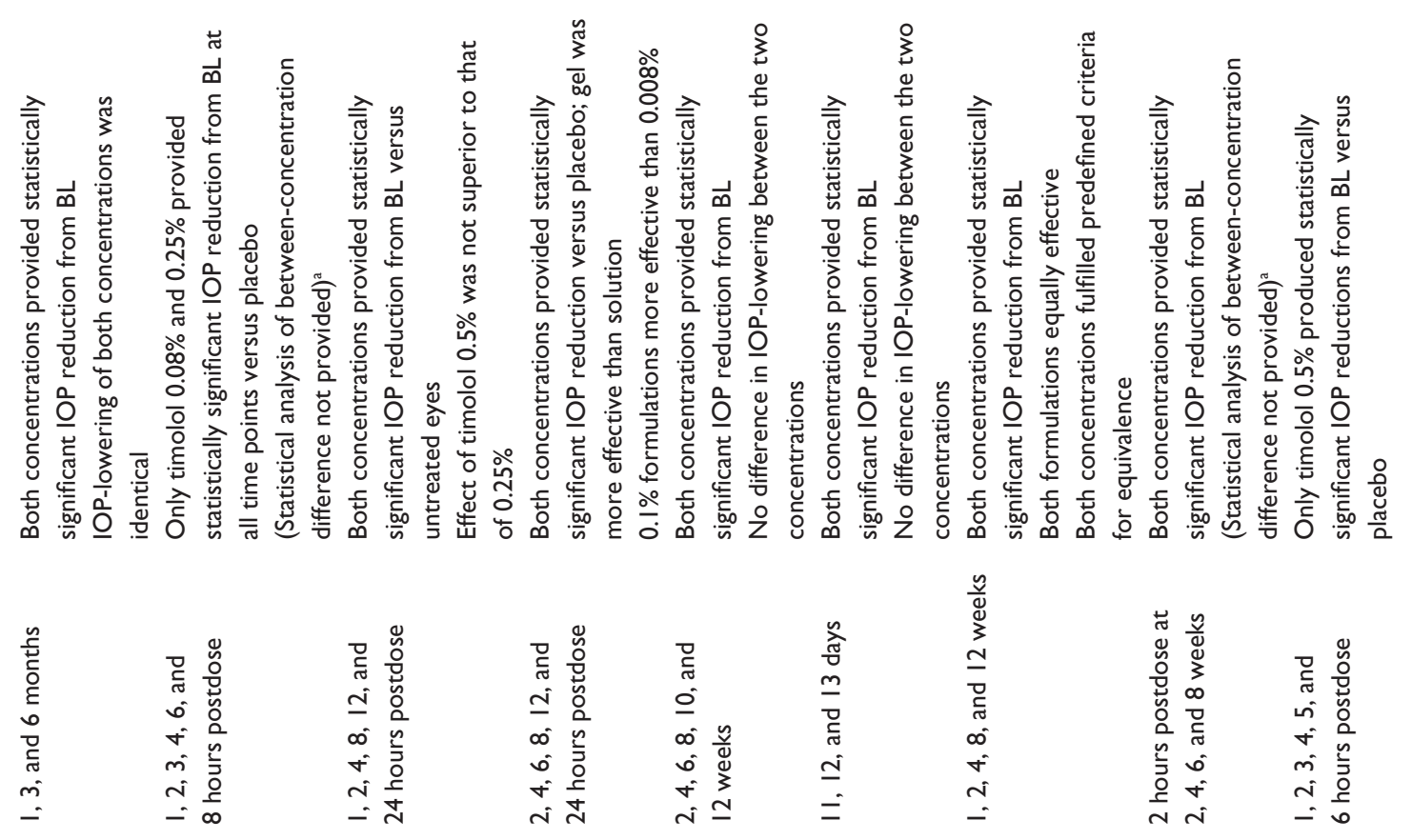

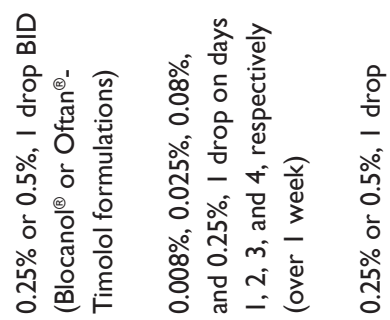

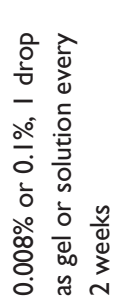

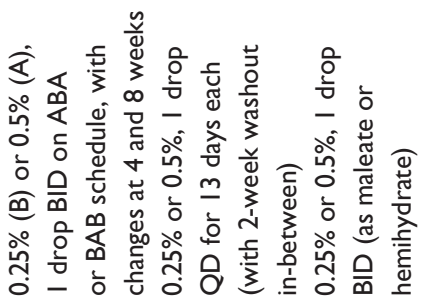

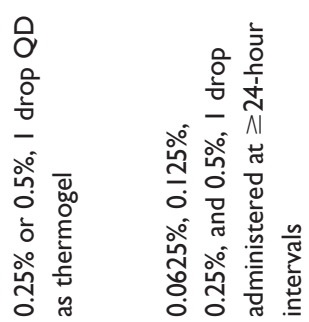

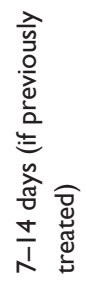
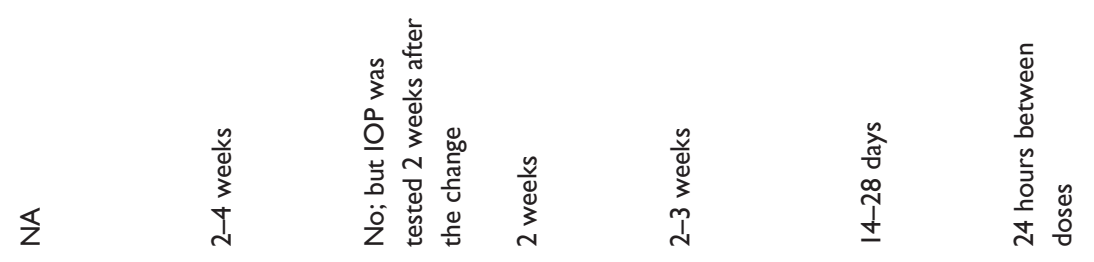

రั 茪定

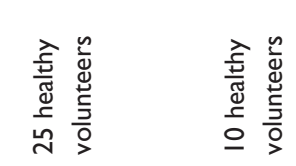

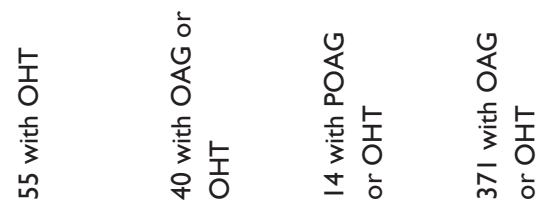

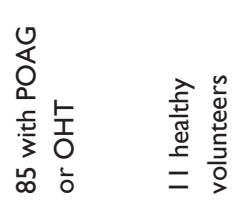
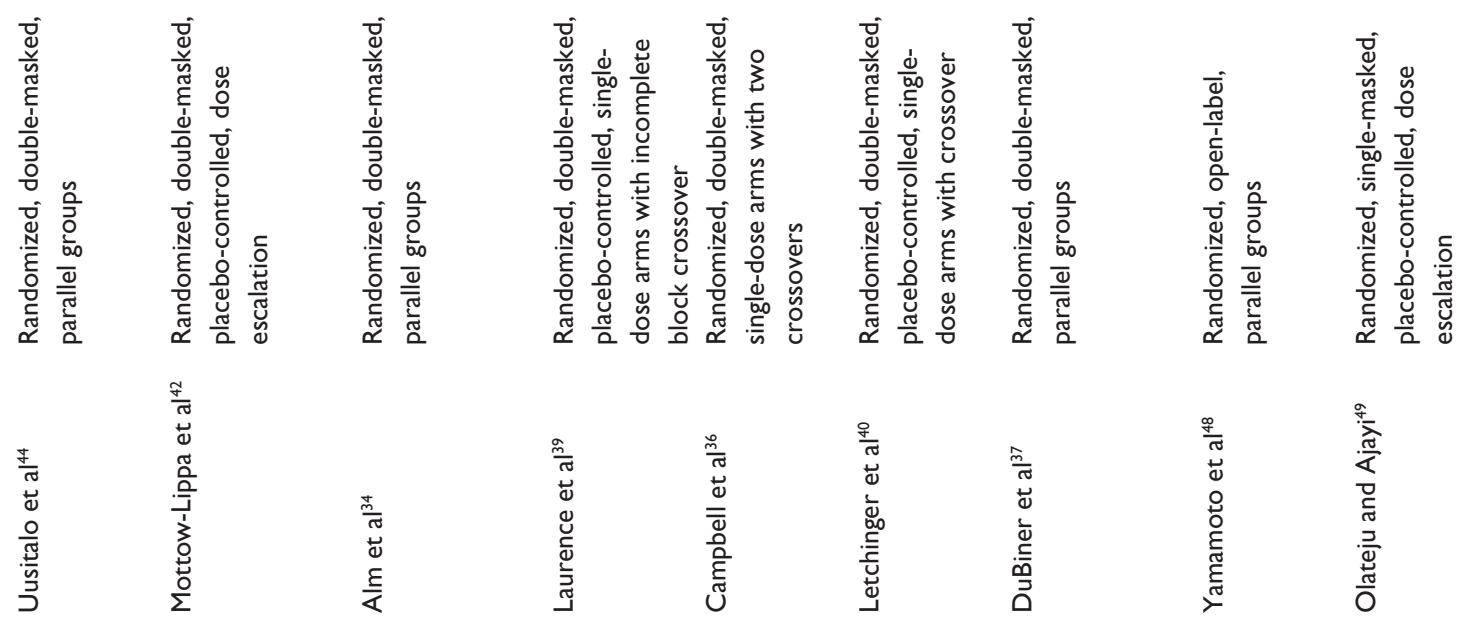


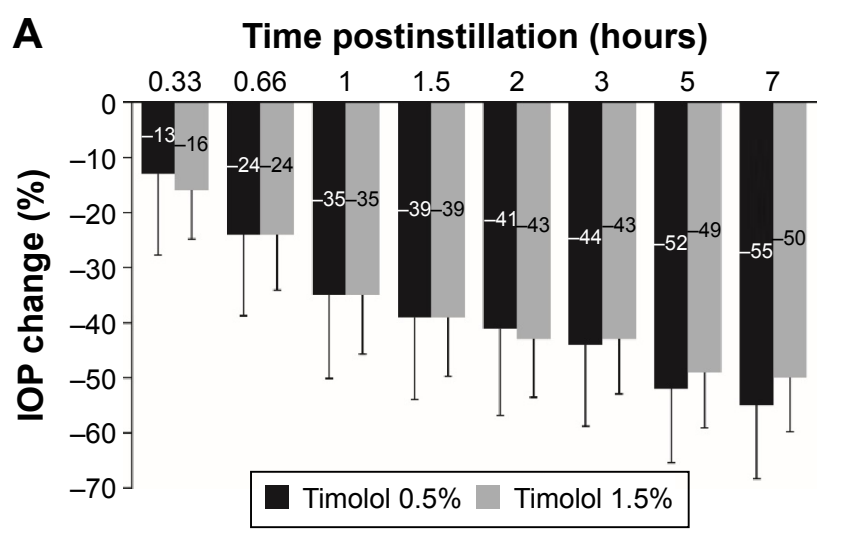

C

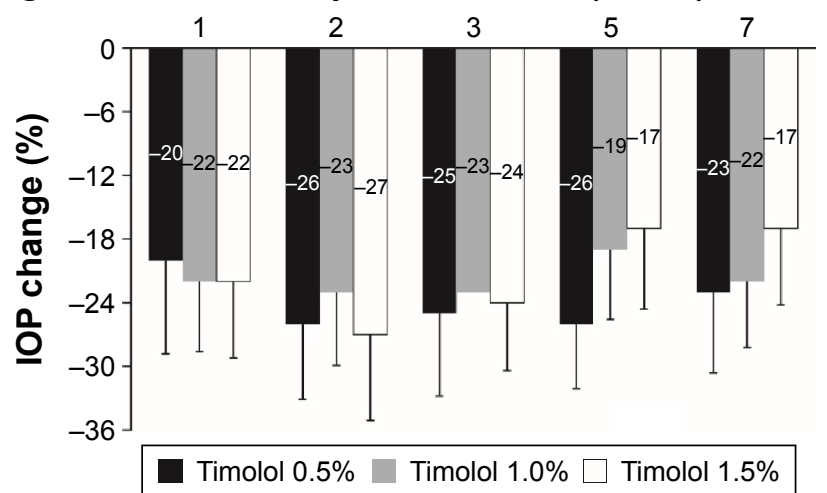

\section{B}

Time postinstillation (hours)

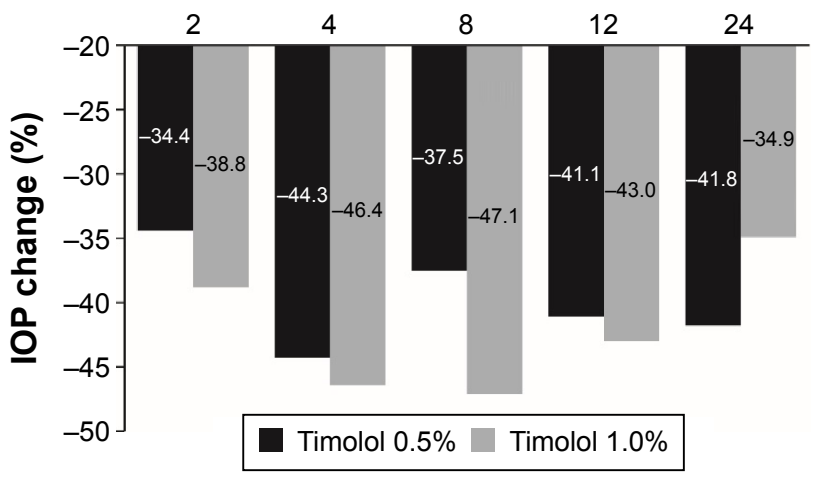

D

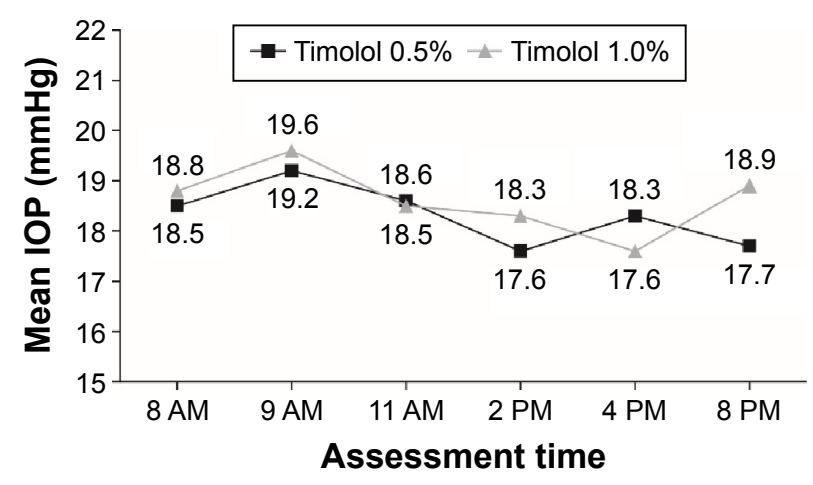

Figure 2 Timolol $0.5 \%$ is at least as effective as timolol $1.0 \%$ and $1.5 \%$ at lowering IOP.

Notes: (A) IOP reduction from baseline in patients with OAG after a single instillation of timolol $0.5 \%(n=15)$ or $1.5 \%$ ( $n=15)$. Based on data from Zimmerman and Kaufman. ${ }^{46}($ B) IOP reduction from baseline in patients with OAG after a single instillation of timolol $0.5 \%(n=9)$ or $1.0 \%$ ( $n=5)$. Based on data from Zimmerman and Kaufman ${ }^{47}$ (standard deviation values were not provided). (C) IOP reduction in healthy volunteers after a single instillation of timolol $0.5 \%$, I.0\%, or I.5\%, relative to placebo treatment. The same participants $(n=15)$ received timolol $0.5 \%, 1 \%$, and I.5\% in a dose-escalating manner on days I, 7, and I4. Based on data from Katz et al. ${ }^{38}$ (D) Mean IOP in patients with OAG or OHT after I week of treatment with timolol $0.5 \%$ or I.0\% twice daily. The same patients ( $\mathrm{n}=\mathrm{I}$ ) received timolol $0.5 \%$ (Phase I) and I.0\% (Phase II) in a doseescalating manner (each treatment lasting I week). Based on data from Zimmerman et $\mathrm{al}^{45}$ (standard deviation values were not provided).

Abbreviations: IOP, intraocular pressure; OAG, open-angle glaucoma; OHT, ocular hypertension.

A Time postinstillation (months)

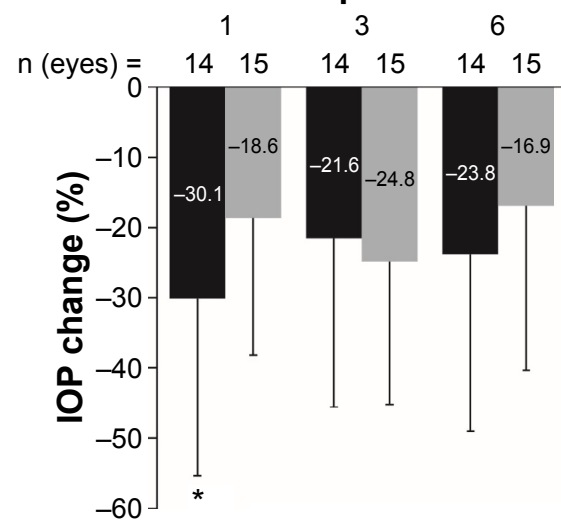

B

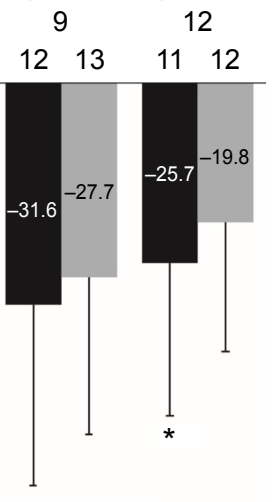

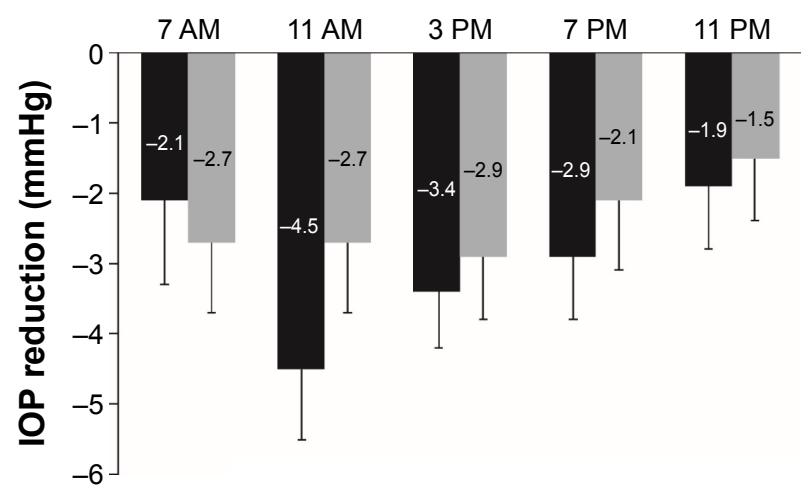

Timolol $0.25 \%$

Timolol $0.5 \%$

Figure 3 IOP lowering with timolol $0.25 \%$ is greater than that with timolol $0.5 \%$.

Notes: (A) IOP reduction from baseline in the right eye of patients with OAG after 12 months of treatment with timolol $0.25 \%$ or $0.5 \%$ twice daily $(* P<0.05$, timolol $0.25 \%$ versus $0.5 \%$ ). Based on data from Mills. ${ }^{41}$ (B) IOP reduction from baseline in patients with primary OAG or OHT after 10 days of treatment with timolol $0.25 \%$ or $0.5 \%$. Patients $(n=14)$ received both treatments in a sequential study design. Based on data from Letchinger et al. ${ }^{40}$

Abbreviations: IOP, intraocular pressure; OAG, open-angle glaucoma; OHT, ocular hypertension. 
effects of timolol $0.25 \%$ and $0.5 \%$ administered once daily for 10 days, reported that timolol $0.25 \%$ was numerically (but not statistically significantly) better than the $0.5 \%$ concentration in lowering IOP over the majority of time points measured (Figure 3B). ${ }^{40}$

Three other studies provided data supporting a dosedependent difference in IOP-lowering favoring the $0.5 \%$ concentration. Results from a 1-week, dose escalation study of twice-daily administration indicated that IOP lowering from baseline was numerically greater with timolol $0.5 \%$ (21\% and 23\%) than with timolol $0.25 \%$ (17\% and $20 \%$ ) at 1 and 6 hours postinstillation, respectively, but similar or greater with timolol $0.25 \%(21 \%$ and $24 \%)$ than with timolol $0.5 \%(21 \%$ and $15 \%)$ at 3 and 8 hours postinstillation, respectively. ${ }^{45}$ However, the IOP-lowering effect appeared to be better sustained at 12 hours postinstillation (trough) with timolol $0.5 \%$ (19\%) than timolol $0.25 \%(11 \%) .{ }^{45}$ Similarly, two short-term studies with assessments that spanned 90 minutes $^{43}$ and 28 hours $^{47}$ postinstillation of timolol $0.25 \%$ or $0.5 \%$ found a dose-dependent, numerical difference in IOP lowering at later time points that favored the $0.5 \%$ concentration (Figure 4), although statistical analysis of the difference between concentrations was not provided.

The remaining eight studies concluded that there was no difference in IOP lowering between timolol $0.25 \%$ and $0.5 \%$. In a double-masked, three-period crossover study of timolol administered twice daily for 4 weeks, the mean IOP reduction at study end was $11.31 \pm 3.18 \mathrm{mmHg}(34.67 \%)$ with timolol $0.25 \%$ versus $12.03 \pm 3.72 \mathrm{mmHg}$ with timolol $0.5 \%$ (35.95\%; $P>0.5) .{ }^{36}$ Findings were comparable when timolol $0.25 \%$ and $0.5 \%$ were dosed once daily for 8 weeks (Figure 5A), ${ }^{48}$ or twice daily for 6 months (Figure 5B). ${ }^{44}$ In a randomized, double-masked, dose escalation study,

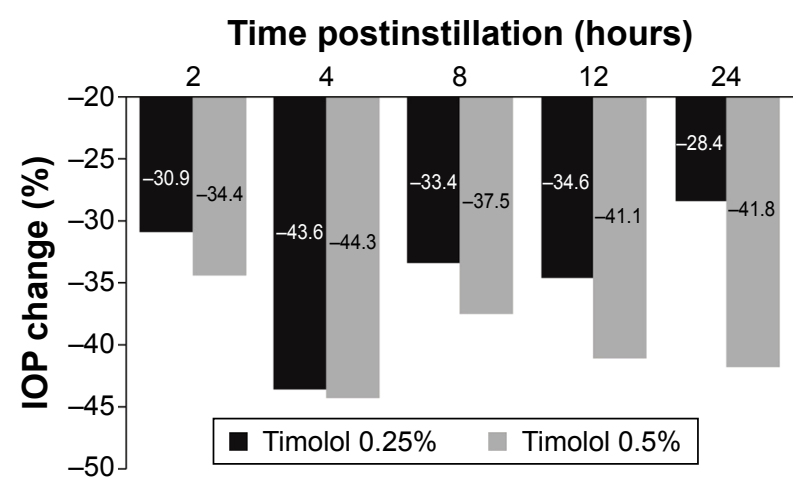

Figure 4 IOP lowering with timolol $0.5 \%$ is greater than that with timolol $0.25 \%$. Notes: IOP reduction from baseline in patients with open-angle glaucoma after a single instillation of timolol $0.25 \%(n=10)$ or $0.5 \%(n=9)$. Based on data from Zimmerman and Kaufman ${ }^{47}$ (standard deviation values were not provided). Abbreviation: IOP, intraocular pressure. timolol $0.25 \%$ induced a $26 \%$ reduction in IOP from baseline when administered twice daily for 1 week. An increase in concentration to timolol $0.5 \%$ only produced a modest, additional IOP reduction of approximately $4 \%$, but a statistical analysis of the between-concentration difference in IOP lowering was not provided. ${ }^{35}$ In a similar dose escalation study of timolol $0.25 \%$ and $0.5 \%$ twice daily, increasing the concentration from $0.25 \%$ to $0.5 \%$ did not result in significant additional IOP lowering from baseline; IOP reduction reached $25 \%$ and $27 \%$ after $3-4$ weeks of treatment with timolol $0.25 \%$ and $0.5 \%$, respectively. ${ }^{33}$ A short-term study that assessed IOP levels at 1, 2, 4, 6, 8, 12, and 24 hours postinstillation and included statistical analysis of the between-concentration difference in IOP lowering from baseline also concluded that the effect of timolol $0.5 \%$ was not superior to that of timolol $0.25 \%$ (Figure 5C). ${ }^{34}$ An area under the curve analysis of IOP versus time (ie, 12 and 24 hours) yielded similar values for both concentrations: $43.6 \pm 6.2$ and $74.9 \pm 11.0$ for timolol $0.25 \%$ versus $38.1 \pm 9.4$ and $69.1 \pm 16.4$ for timolol $0.5 \%$, respectively. ${ }^{34}$ Importantly, the largest study identified in this systematic review compared the IOP-lowering efficacy of timolol $0.25 \%$ and $0.5 \%$ administered twice daily as a maleate or hemihydrate solution over 8 weeks in 371 patients with POAG or OHT. ${ }^{37}$ The authors concluded that when either formulation was administered, the $0.25 \%$ and $0.5 \%$ dose strengths were equally effective from week 1 to week 12 (Figure 5D); equivalence between the two concentrations at the final visit was established by statistical analysis.

Taken together, the aforementioned results suggest that an inverted U-shaped dose-response curve may exist for timolol in terms of IOP lowering, and that the concentration that elicits maximum IOP lowering likely lies between $0.25 \%$ and $0.5 \%$, as illustrated in Figure 6. A possible explanation for the inverted U-shaped dose-response curve might involve receptor upregulation and tachyphylaxis. The association between repeated ocular timolol use and tachyphylaxis has long been described, ${ }^{57-65}$ and although some patients exhibit relatively stable IOP reductions for years in response to timolol ophthalmic solution, some demonstrate an upward IOP drift after days or months, reflecting a partial or complete loss of response to timolol. ${ }^{59,62}$ Timolol concentrations of $0.5 \%$ and higher may be associated with an increased occurrence of receptor upregulation, ${ }^{62,66,67}$ which leads to tachyphylaxis. In contrast, there has been no report of an association between bimatoprost and tachyphylaxis in the literature, and preclinical studies of bimatoprost in dogs and monkeys have revealed a flat dose-response curve between $0.001 \%$ 
A

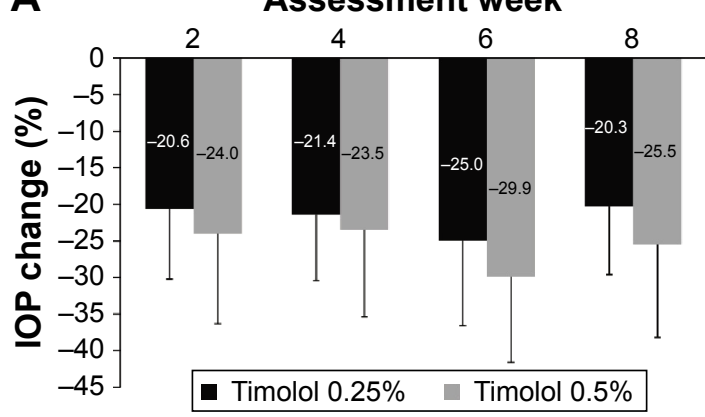

C

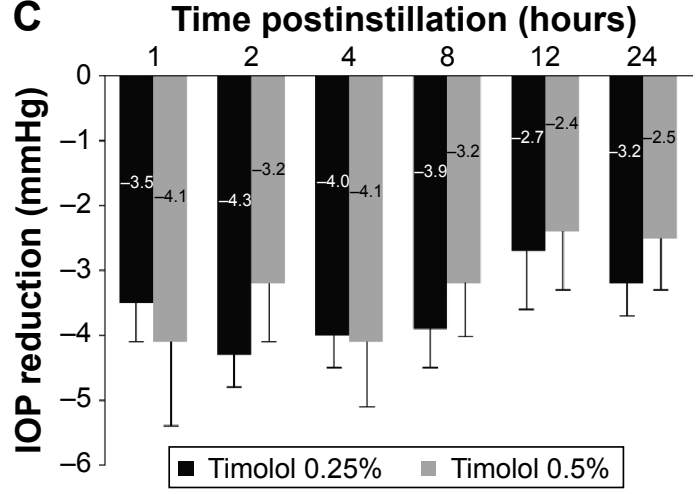

B

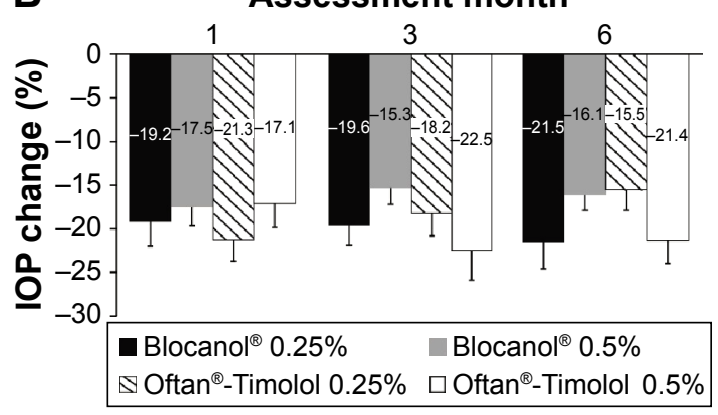

D

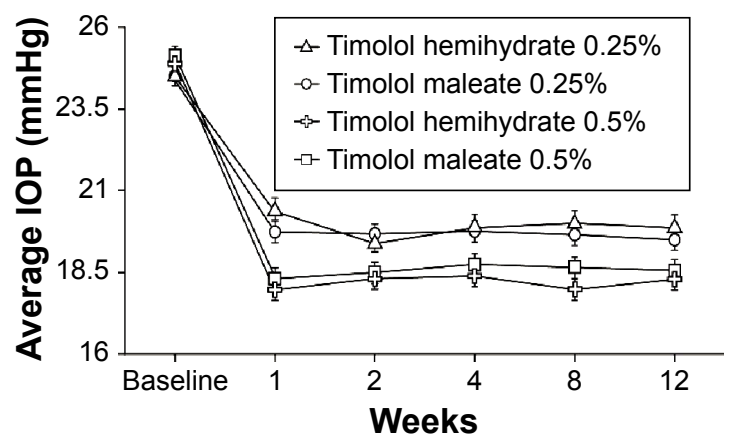

Figure 5 IOP lowering is similar with timolol $0.25 \%$ and $0.5 \%$.

Notes: (A) IOP reduction from baseline in patients with OAG or OHT after 8 weeks of treatment with timolol $0.25 \%$ ( $n=46)$ or $0.5 \%$ ( $n=39)$ twice daily. Based on data from Yamamoto et al..$^{48}$ (B) IOP reduction from baseline in patients with OAG or OHT after 6 months of treatment with Blocanol ${ }^{\otimes} 0.25 \%(n=14)$, Oftan ${ }^{\circledR}-$ Timolol $0.25 \%$ $(n=13)$, Blocanol ${ }^{\circledR} 0.5 \%(n=15)$, or Oftan ${ }^{\circledR}$-Timolol $0.5 \%(n=15)$ twice daily. Blocanol ${ }^{\circledR}$ and Oftan ${ }^{\circledR}$-Timolol are formulations of timolol available commercially (trademarks of Merck \& Co, Kenilworth, NJ, USA, and Santen Pharmaceuticals, Emeryville, CA, USA, respectively). Based on data from Uusitalo et al. ${ }^{44}$ (C) IOP reduction from baseline in healthy volunteers following a single application of timolol. All participants $(n=10)$ received both concentrations in a randomized sequence, with a I-week washout period between treatments. Based on data from Alm et al. ${ }^{34}(\mathrm{D})$ IOP at baseline and after treatment with timolol hemihydrate $0.25 \%(n=91)$, timolol maleate $0.25 \%(n=92)$, timolol hemihydrate $0.5 \%(n=93)$, or timolol maleate $0.5 \%(n=95) .{ }^{37}$ Reprinted from Am J Ophthalmol, I2I/5, DuBiner HB, Hill R, Kaufman H, et al, Timolol hemihydrate vs timolol maleate to treat ocular hypertension and open-angle glaucoma, 522-528, Copyright 1996, with permission from Elsevier. ${ }^{37} \mathrm{http}: / /$ www.ajo.com/.

Abbreviations: IOP, intraocular pressure; OAG, open-angle glaucoma; OHT, ocular hypertension.

and $0.1 \%$, suggesting that preservative removal is unlikely to affect the effective concentration of bimatoprost. ${ }^{68}$

\section{Conclusion}

The evidence gathered appears to support our hypothesis that the optimal IOP-lowering concentration of timolol lies

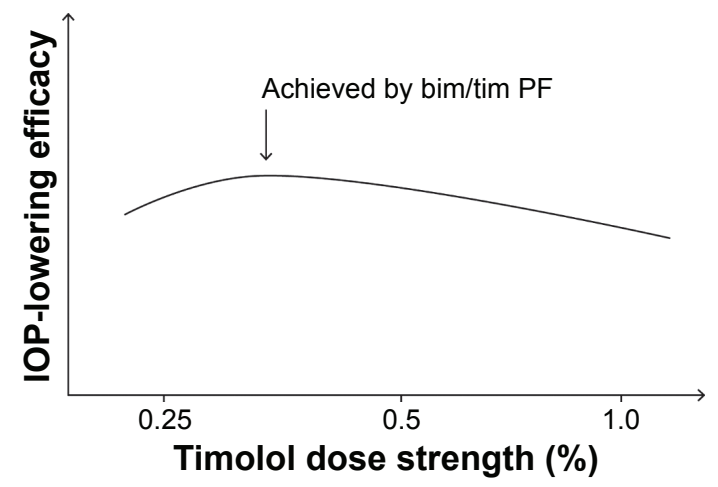

Figure 6 Illustration of the inverted, U-shaped dose-response curve for the IOPlowering effect of timolol.

Abbreviations: bim/tim, bimatoprost/timolol; IOP, intraocular pressure; PF, preservative-free. between $0.25 \%$ and $0.5 \%$ when administered as a BAKpreserved formulation. The majority of studies found no significant differences in IOP lowering between the $0.25 \%$ and $0.5 \%$ concentrations, and some studies showed statistically significantly increased efficacy with the $0.25 \%$ concentration. Therefore, if the removal of BAK would result in lower ocular concentrations of timolol in patients treated with $\mathrm{bim} /$ tim PF (containing 0.5\% timolol) than in those treated with preserved bim/tim (also containing $0.5 \%$ timolol), it is reasonable to believe that the reduced exposure to timolol $0.5 \%$ in the PF formulation at the target site may bring the effective concentration within the $0.25 \%-0.5 \%$ range, thus maximizing the IOP-lowering effect of timolol. This supposition, however, should be considered in light of the limitations of the available data: the variability of the study designs, the small sample sizes of some studies, and the lack of studies that compared the efficacy of various concentrations of timolol in preserved versus PF formulations.

Timolol ophthalmic solution was a much needed breakthrough for the treatment of OAG. Early pharmacokinetic 
and pharmacodynamic studies showed that timolol is well absorbed through the cornea and rapidly distributes into ocular tissues following topical ocular administration; it can be measured in the human aqueous humor for up to 12 hours. Timolol significantly lowered IOP in healthy volunteers and in patients with $\mathrm{OAG}$, and in dose ranging studies, the maximum effect appeared to occur with the $0.5 \%$ concentration. ${ }^{69}$ The current knowledge of the doseresponse relationship between IOP lowering and timolol concentration in preserved topical ophthalmic solutions is highlighted in our systematic literature review. Studies that evaluated the efficacy of timolol over weeks or months in patients with OAG or OHT are likely more relevant to our hypothesis as they are indicative of the relationship between efficacy and steady-state concentrations of timolol in the eye (compared with studies assessing the IOP-lowering effects within minutes or hours of treatment with a single dose). These studies concluded that timolol ophthalmic solutions at $0.1 \%, 0.25 \%, 0.5 \%$, and/or $1 \%$ provide statistically significant IOP reductions from baseline and/or compared with untreated or placebo-treated eyes, regardless of the instillation schedule. Nevertheless, all but two short-term studies (including one study in eleven patients that could not detect significant IOP reduction at every time point with timolol $0.5 \%$ ), reached the same conclusion, even for timolol concentrations $\leq 0.1 \%$.

Overall, these data suggest that on a concentration basis, timolol $0.5 \%$ is more effective at lowering IOP than higher concentrations, and that the optimal IOP-lowering concentration of timolol is likely between $0.25 \%$ and $0.5 \%$. Furthermore, these findings support the clinical observation that removal of BAK from the bim/tim formulation provided more optimal IOP reduction.

\section{Acknowledgments}

This article was sponsored by Allergan plc. Medical writing and editorial assistance was provided to the authors by Michele Jacob, PhD, and Jennifer Bodkin, PhD, of Evidence Scientific Solutions (Philadelphia, PA, USA), and funded by Allergan plc.

\section{Disclosure}

Jie Shen and Marina Bejanian are employees of Allergan plc. The authors report no other conflicts of interest in this work.

\section{References}

1. Quigley HA, Broman AT. The number of people with glaucoma worldwide in 2010 and 2020. Br J Ophthalmol. 2006;90(3):262-267.
2. Bagnis A, Papadia M, Scotto R, Traverso CE. Current and emerging medical therapies in the treatment of glaucoma. Expert Opin Emerg Drugs. 2011;16(2):293-307.

3. American Academy of Ophthalmology. Preferred Practice Pattern ${ }^{\circledR}$ Guidelines. Primary Open-Angle Glaucoma [homepage on the Internet]. San Francisco, CA: American Academy of Ophthalmology (AAO) Glaucoma Panel; 2010. Available from: http://www.aaojournal.org/ article/S0161-6420(15)01276-2/pdf. Accessed January 29, 2016.

4. Marquis RE, Whitson JT. Management of glaucoma: focus on pharmacological therapy. Drugs Aging. 2005;22(1):1-21.

5. McKinnon SJ, Goldberg LD, Peeples P, Walt JG, Bramley TJ. Current management of glaucoma and the need for complete therapy. Am J Manag Care. 2008;14(Suppl 1):S20-S27.

6. Stamper RL. Introduction and classification of the glaucomas. In: Stamper RL, Lieberman MF, Drake MV, editors. Becker-Shaffer's Diagnosis and Therapy of the Glaucomas. 8th ed. Amsterdam, the Netherlands: Mosby Elsevier; 2009:1-7.

7. Louati Y, Shaarawy T. Controversy: is benzalkonium chloride necessary in antiglaucoma drops? J Curr Glaucoma Pract. 2012;6(3): 104-107.

8. Noecker R, Miller KV. Benzalkonium chloride in glaucoma medications. Ocul Surf. 2011;9(3):159-162.

9. Baudouin C, Labbé A, Liang H, Pauly A, Brignole-Baudouin F. Preservatives in eyedrops: the good, the bad and the ugly. Prog Retin Eye Res. 2010;29(4):312-334.

10. Trocme S, Hwang LJ, Bean GW, Sultan MB. The role of benzalkonium chloride in the occurrence of punctate keratitis: a meta-analysis of randomized, controlled clinical trials. Ann Pharmacother. 2010;44(12): 1914-1921.

11. Leung EW, Medeiros FA, Weinreb RN. Prevalence of ocular surface disease in glaucoma patients. J Glaucoma. 2008;17(5):350-355.

12. Stewart WC, Stewart JA, Nelson LA. Ocular surface disease in patients with ocular hypertension and glaucoma. Curr Eye Res. 2011;36(5): 391-398.

13. de Jong C, Stolwijk T, Kuppens E, de Keizer R, van Best J. Topical timolol with and without benzalkonium chloride: epithelial permeability and autofluorescence of the cornea in glaucoma. Graefes Arch Clin Exp Ophthalmol. 1994;232(4):221-224.

14. Bron A, Velasque L, Rebica H, Pouliquen P, Elena PP, Rouland JF. Comparaison du timolol sans conservateur et du timolol à délivrance prolongée donnés une fois par jour en association à du latanoprost. [Comparison of once-daily nonpreserved timolol and timolol maleate gel-forming solution associated with latanoprost]. J Fr Ophthalmol. 2004;27(9 Pt 1):971-977. French.

15. Frezzotti P, Fogagnolo P, Haka G, et al. In vivo confocal microscopy of conjunctiva in preservative-free timolol $0.1 \%$ gel formulation therapy for glaucoma. Acta Ophthalmol. 2014;92(2):e133-e140.

16. Manni G, Centofanti M, Oddone F, Parravano M, Bucci MG. Interleukin- $1 \beta$ tear concentration in glaucomatous and ocular hypertensive patients treated with preservative-free nonselective beta-blockers. Am J Ophthalmol. 2005;139(1):72-77.

17. Mastropasqua L, Agnifili L, Fasanella V, et al. Conjunctival goblet cells density and preservative-free tafluprost therapy for glaucoma: an in vivo confocal microscopy and impression cytology study. Acta Ophthalmol. 2013;91(5):e397-e405.

18. Rouland JF, Traverso CE, Stalmans I, et al; for the T2345 Study Group. Efficacy and safety of preservative-free latanoprost eyedrops, compared with BAK-preserved latanoprost in patients with ocular hypertension or glaucoma. Br J Opthalmol. 2013;97(2):196-200.

19. Uusitalo H, Kaarniranta K, Ropo A. Pharmacokinetics, efficacy and safety profiles of preserved and preservative-free tafluprost in healthy volunteers. Acta Ophthalmol Suppl (Oxf). 2008;242:7-13.

20. Jaenen N, Baudouin C, Pouliquen P, Manni G, Figueiredo A, Zeyen T. Ocular symptoms and signs with preserved and preservative-free glaucoma medications. Eur J Ophthalmol. 2007;17(3):341-349.

21. Pisella PJ, Pouliquen P, Baudouin C. Prevalence of ocular symptoms and signs with preserved and preservative free glaucoma medication. Br J Ophthalmol. 2002;86(4):418-423. 
22. Bron A, Chiambaretta F, Pouliquen P, Rigal D, Rouland JF. Intérêt de la substitution d'un traitement journalier de 2 instillations de timolol par 1 instillation quotidienne de bêtabloquant non conservé chez des patients présentant un glaucome chronique ou une hypertonie oculaire [Efficacy and safety of substituting a twice-daily regimen of timolol with a single daily instillation of nonpreserved beta-blocker in patients with chronic glaucoma or ocular hypertension]. J Fr Ophtalmol. 2003;26(7):668-674. French.

23. European Medicines Agency. Ganfort ${ }^{\circledR}$ - Summary of Product Characteristics [homepage on the Internet]. Irvine, CA: Allergan, plc; 2006. Available from: http://www.ema.europa.eu/docs/en_GB/ document_library/EPAR_-_Product_Information/human/000668/ WC500020625.pdf. Accessed April 2, 2015.

24. Brandt JD, Cantor LB, Katz LJ, Batoosingh AL, Chou C, Bossowska I; for the Ganfort Investigators Group II. Bimatoprost/timolol fixed combination: a 3-month double-masked, randomized parallel comparison to its individual components in patients with glaucoma or ocular hypertension. J Glaucoma. 2008;17(3):211-216.

25. Lewis RA, Gross RL, Sall KN, Schiffman RM, Liu CC, Batoosingh AL; for the Ganfort Investigators Group II. The safety and efficacy of bimatoprost/timolol fixed combination: a 1-year double-masked, randomized parallel comparison to its individual components in patients with glaucoma or ocular hypertension. J Glaucoma. 2010;19(6): 424-426.

26. Goldberg I, Gil Pina R, Lanzagorta-Aresti A, Schiffman RM, Liu C, Bejanian M. Bimatoprost $0.03 \% /$ timolol 0.5\% preservative-free ophthalmic solution versus bimatoprost $0.03 \% /$ timolol $0.5 \%$ ophthalmic solution (Ganfort) for glaucoma or ocular hypertension: a 12-week randomised controlled trial. Br J Ophthalmol. 2014;98(7):926-931.

27. European Medicines Agency. Summary of the European Public Assessment Report (EPAR) for Ganfort (Bimatoprost/Timolol) [homepage on the Internet]. London, UK: EMA Committee for Medicinal Products for Human Use (CHMP); 2013. Available from: http://www.ema.europa. eu/ema/index.jsp?curl=pages/medicines/human/medicines/000668/ human_med_000804.jsp\&mid=WC0b01ac058001d124. Accessed April 1, 2015.

28. Okabe K, Kimura H, Okabe J, et al. Effect of benzalkonium chloride on transscleral drug delivery. Invest Ophthalmol Vis Sci. 2005;46(2): 703-708.

29. Desbenoit N, Schmitz-Afonso I, Baudouin C, et al. Localisation and quantification of benzalkonium chloride in eye tissue by TOF-SIMS imaging and liquid chromatography mass spectrometry. Anal Bioanal Chem. 2013;405(12):4039-4049.

30. van der Bijl P, van Eyk AD, Meyer D. Effects of three penetration enhancers on transcorneal permeation of cyclosporine. Cornea. 2001; 20(5):505-508.

31. Pellinen P, Huhtala A, Tolonen A, Lokkila J, Mäenpää J, Uusitalo H. The cytotoxic effects of preserved and preservative-free prostaglandin analogs on human corneal and conjunctival epithelium in vitro and the distribution of benzalkonium chloride homologs in ocular surface tissues in vivo. Curr Eye Res. 2012;37(2):145-154.

32. Shen J, Bejanian M, Schiffman R. Removal of preservative from Ganfort improves intraocular pressure (IOP) lowering in patients - a timolol dose-response phenomenon. Acta Ophthalmol (Copenh). 2013;91(s252): Abstract 4226. Available from: http://onlinelibrary.wiley.com/doi/10.1111/ j.1755-3768.2013.4226.x/abstract. Accessed January 8, 2016.

33. Krupin T, Singer PR, Perlmutter J, Kolker AE, Becker B. One-hour intraocular pressure response to timolol. Lack of correlation with longterm response. Arch Ophthalmol. 1981;99(5):840-841.

34. Alm A, Koskela T, Taarnhøj J. Effects of D-timolol and L-timolol eye drops on intraocular pressure and aqueous flow. A dose-response study in normal eyes. Acta Ophthalmol (Copenh). 1990;68(1):19-22.

35. Batchelor ED, O'Day DM, Shand DG, Wood AJ. Interaction of topical and oral timolol in glaucoma. Ophthalmology. 1979;86(1):60-65.

36. Campbell SH, Hickey-Dwyer M, Harding SP. Double-masked threeperiod crossover investigation of timolol in control of raised intraocular pressure. Eye (Lond). 1993;7(1):105-108.
37. DuBiner HB, Hill R, Kaufman H, et al. Timolol hemihydrate vs timolol maleate to treat ocular hypertension and open-angle glaucoma. Am J Ophthalmol. 1996;121(5):522-528.

38. Katz IM, Hubbard WA, Getson AJ, Gould AL. Intraocular pressure decrease in normal volunteers following timolol ophthalmic solution. Invest Ophthalmol. 1976;15(6):489-492.

39. Laurence J, Holder D, Vogel R, et al. A double-masked, placebocontrolled evaluation of timolol in a gel vehicle. J Glaucoma. 1993;2(3): 177-182.

40. Letchinger SL, Frohlichstein D, Glieser DK, et al. Can the concentration of timolol or the frequency of its administration be reduced? Ophthalmology. 1993;100(8):1259-1262.

41. Mills KB. Blind randomised non-crossover long-term trial comparing topical timolol $0.25 \%$ with timolol $0.5 \%$ in the treatment of simple chronic glaucoma. Br J Ophthalmol. 1983;67(4):216-219.

42. Mottow-Lippa LS, Lippa EA, Naidoff MA, Clementi R, Bjornsson T, Jones K. 008\% timolol ophthalmic solution. A minimal-effect dose in a normal volunteer model. Arch Ophthalmol. 1990;108(1):61-64.

43. Rowley S, Staunton JE, Tosch A, Stewart-Jones JH, Edgar DF, Turner P. A noninvasive tonometer in the measurement of the effects of pindolol and timolol on intraocular pressure in normal subjects. Br JOphthalmol. 1981;65(8):536-538.

44. Uusitalo RJ, Palkama A, Stjernschantz J. A study of the efficacy of two commercial preparations of timolol maleate with special reference to side effects. Acta Ophthalmol (Copenh). 1985;63(6):634-641.

45. Zimmerman TJ, Kass MA, Yablonski ME, Becker B. Timolol maleate: efficacy and safety. Arch Ophthalmol. 1979;97(4):656-658.

46. Zimmerman TJ, Kaufman HE. Timolol: a $\beta$-adrenergic blocking agent for the treatment of glaucoma. Arch Ophthalmol. 1977;95(4):601-604.

47. Zimmerman TJ, Kaufman HE. Timolol: dose response and duration of action. Arch Ophthalmol. 1977;95(4):605-607.

48. Yamamoto T, Kitazawa Y, Azuma I, Tsukahara S, Nakashima M; for the WP-934 Study Group. Clinical evaluation of a new formula of timolol maleate (WP-934 ophthalmic solution). Jpn J Opthalmol. 1997; 41(4):244-250

49. Olateju SO, Ajayi AA. The lack of efficacy of topical beta-blockers, timolol and betaxolol on intraocular pressure in Nigerian healthy volunteers. Eye (Lond). 1999;13(Pt 6):758-763.

50. Le Jeunne CL, Hugues FC, Dufier JL, Munera Y, Bringer L. Bronchial and cardiovascular effects of ocular topical B-antagonists in asthmatic subjects: comparison of timolol, carteolol, and metipranolol. J Clin Pharmacol. 1989;29(2):97-101.

51. Leier CV, Baker ND, Weber PA. Cardiovascular effects of ophthalmic timolol. Ann Intern Med. 1986;104(2):197-199.

52. Nelson WL, Fraunfelder FT, Sills JM, Arrowsmith JB, Kuritsky JN. Adverse respiratory and cardiovascular events attributed to timolol ophthalmic solution, 1978-1985. Am J Ophthalmol. 1986;102(5): 606-611.

53. Netland PA, Weiss HS, Stewart WC, Cohen JS, Nussbaum LL; for the Night Study Group. Cardiovascular effects of topical carteolol hydrochloride and timolol maleate in patients with ocular hypertension and primary open-angle glaucoma. Am J Opthalmol. 1997; 123(4):465-477.

54. Stewart WC, Stewart JA, Jackson AL. Cardiovascular effects of timolol maleate, brimonidine or brimonidine/timolol maleate in concomitant therapy. Acta Ophthalmol Scand. 2002;80(3):277-281.

55. Umetsuki MH, Kotegawa T, Nakamura K, Nakano S, Nakatsuka K. Temporal variation in the effects of ophthalmic timolol on cardiovascular and respiratory functions in healthy men. J Clin Pharmacol. 1997;37(1): $58-63$.

56. Sica DA. Pharmacotherapy in congestive heart failure: cardiopulmonary effects of ophthalmically administered beta-blockers. Congest Heart Fail. 1999;5(2):81-85.

57. Zimmerman TJ, Canale P. Timolol-further observations. Ophthalmology. 1979;86(1):166-169.

58. Kosman ME. Timolol in the treatment of open angle glaucoma. JAMA. 1979;241(21):2301-2303. 
59. Ros FE, Dake CL. Timolol eye drops: bradycardia or tachycardia? Doc Ophthalmol. 1980;48(2):283-289.

60. Cher I. Transfer to timolol: selective use of a new mode of therapy. Aust J Ophthalmol. 1980;8(2):165-172.

61. Steinert RF, Thomas JV, Boger WP 3rd. Long-term drift and continued efficacy after multiyear timolol therapy. Arch Ophthalmol. 1981;99(1): 100-103.

62. Boger WP 3rd. Shortterm "escape" and longterm "drift." The dissipation effects of the beta adrenergic blocking agents. Surv Ophthalmol. 1983;28(Suppl):235-242.

63. Maclure GM. Chronic open angle glaucoma treated with Timolol. A four year study. Trans Ophthalmol Soc U K. 1983;103(Pt 1):78-83.

64. Gandolfi SA. Restoring sensitivity to timolol after long-term drift in primary open-angle glaucoma. Invest Ophthalmol Vis Sci. 1990;31(2): 354-358.

65. Gandolfi SA, Vecchi M. Serial administration of adrenergic antagonist and agonist ("pulsatile therapy") reduces the incidence of long-term drift to timolol in humans. Invest Ophthalmol Vis Sci. 1996;37(4): 684-688.
66. Neufeld AH, Zawistowski KA, Page ED, Bromberg BB. Influences on the density of beta-adrenergic receptors in the cornea and iris - ciliary body of the rabbit. Invest Ophthalmol Vis Sci. 1978;17(11):1069-1075.

67. Kahle G, Kaulen P, Scherer V, Wollensak J. Zunahme der betaadrenergen rezeptoren in kaninchen in langfristige lokale verabreichung von betablockern. [Increase in beta-adrenergic receptors in rabbits in long-term local administration of beta-blockers]. Ophthalmologe. 1993;90(6):626-630. German

68. Woodward DF, Phelps RL, Krauss AH, et al. Bimatoprost: a novel antiglaucoma agent. Cardiovasc Drug Rev. 2004;22(2):103-120.

69. Heel RC, Brogden RN, Speight TM, Avery GS. Timolol: a review of its therapeutic efficacy in the topical treatment of glaucoma. Drugs. 1979;17(1):38-55.
Clinical Ophthalmology

\section{Publish your work in this journal}

Clinical Ophthalmology is an international, peer-reviewed journal covering all subspecialties within ophthalmology. Key topics include: Optometry; Visual science; Pharmacology and drug therapy in eye diseases; Basic Sciences; Primary and Secondary eye care; Patien Safety and Quality of Care Improvements. This journal is indexed on

Submit your manuscript here: http://www.dovepress.com/clinical-ophthalmology-journal

\section{Dovepress}

PubMed Central and CAS, and is the official journal of The Society of Clinical Ophthalmology (SCO). The manuscript management system is completely online and includes a very quick and fair peer-review system, which is all easy to use. Visit http://www.dovepress.com/ testimonials.php to read real quotes from published authors. 